\title{
Prevalência e perfil de sensibilidade antimicrobiana de bactérias isoladas de pacientes internados em Unidade de Terapia Intensiva de um hospital universitário do Sertão de Pernambuco
}

\author{
Prevalence and profile of antimicrobial sensitivity of bacteria \\ isolated from patients hospitalized in an Intensive Care Unit \\ of a university hospital in Hinterland of Pernambuco
}

\author{
Maria Ianne Moreira Leite ${ }^{1}$, Carine Freitas Silva ${ }^{2}$, \\ Andréa Colombo ${ }^{3}$, Carine Rosa Naue ${ }^{4}$
}

Resumo

\begin{abstract}
O objetivo desse trabalho foi determinar a prevalência e o perfil de sensibilidade das espécies bacterianas isoladas de pacientes internados na Unidade de Terapia Intensiva (UTI) de um hospital universitário do Sertão de Pernambuco. Foi realizado um estudo retrospectivo através da análise descritiva dos resultados do diagnóstico microbiológico laboratorial do próprio serviço, provenientes de hemoculturas, uroculturas e aspirados traqueais dos pacientes internados na UTI, durante o período de janeiro a junho de 2019. No total, 394 amostras clínicas foram obtidas, divididas entre hemoculturas, uroculturas e aspirados traqueais; destas, 144 foram positivas para espécies bacterianas. O aspirado traqueal foi o material clínico com maior percentual de culturas positivas $(67,4 \%)$. A bactéria mais prevalente isolada dos indivíduos na UTI foi Acinetobacter baumannii $(22,9 \%)$, seguida de Pseudomonas aeruginosa (19,2\%), Staphylococcus aureus (16,7\%), Klebsiella pneumoniae (15,2\%) e Staphylococcus coagulase negativa (SCN- 8,3\%). A maioria das espécies isoladas apresentou um perfil de sensibilidade reduzido aos fármacos beta-lactâmicos, especialmente ampicilina, penicilina e carbapênemicos, independente da amostra clínica. Os bacilos Gram-negativos (BGN) apresentaram elevada sensibilidade à colistina. As informações deste estudo permitem reconhecer a frequência das espécies de bactérias mais isoladas envolvidas em infecções relacionadas à assistência à saúde (IRAS) na UTI e poderão nortear o tratamento das infecções e diminuir a pressão seletiva de bactérias multirresistentes, servindo como modelo assistencial na vigilância, bem como no controle das IRAS.
\end{abstract}

Palavras-chave: Anti-infecciosos. Unidade de Terapia Intensiva. Bactérias.

\footnotetext{
${ }^{1}$ Graduação em Ciências Farmacêuticas pela Universidade Federal do Vale do São Francisco (Univasf), Petrolina, Pernambuco, Brasil.

${ }^{2}$ Graduanda em Fisioterapia na Faculdade São Francisco de Juazeiro (FASJ), Juazeiro, Bahia, Brasil.

${ }^{3}$ Doutorado em Ciências (Microbiologia) pela Universidade Federal do Rio de Janeiro (UFRJ), Rio de Janeiro, Rio de Janeiro, Brasil. Professora Adjunta do Curso de Ciências Farmacêuticas da Universidade Federal do Vale do São Francisco, Petrolina, Pernambuco, Brasil.

${ }^{4}$ Doutorado em Fitopatologia e Bacteriologia pela Universidade Federal Rural de Pernambuco (UFRPE), Recife, Pernambuco, Brasil. Microbiologista do Laboratório de Análises Clínicas da Empresa Brasileira de Serviços Hospitalares (Ebserh) no Hospital Universitário da Universidade Federal do Vale do São Francisco (HU-Univasf), Petrolina, Pernambuco, Brasil. E-mail: crnaue@yahoo.com.br
} 


\begin{abstract}
The aim of this study was to determine the prevalence and sensitivity profile of bacterial species isolated from patients admitted to the Intensive Care Unit (ICU) of a university hospital in Hinterland of Pernambuco. A retrospective study was carried out through the descriptive analysis of the results at the microbiological laboratory diagnosis of the service itself, from blood cultures, urine cultures and tracheal aspirates of patients admitted to the ICU, during the period from January to June 2019. A total of 394 clinical samples were obtained, divided between blood cultures, urocultures and tracheal aspirates, of which 144 were positive for bacterial species. Tracheal aspirate was the clinical material with the highest percentage of positive cultures (67.4\%). The most prevalent bacterium isolated from individuals in the ICU was Acinetobacter baumannii (22.9\%), followed by Pseudomonas aeruginosa (19.2\%), Staphylococcus aureus (16.7\%), Klebsiella pneumoniae (15.2\%) and Staphylococcus coagulase-negative (SCN- 8.3\%). Most isolated species showed a reduced sensitivity profile to betalactam drugs, especially ampicillin, penicillin and carbapenems, regardless of the clinical sample. Gram-negative bacilli (GNB) were highly sensitive to colistin. The information in this study allows us to recognize the frequency of the most isolated bacterial species involved in healthcare-associated infections (HAIs) in the ICU and may guide the treatment of infections and reduce the selective pressure of multiresistant bacteria, serving as an assistance model in surveillance as well as in the control of HAIs.
\end{abstract}

Keywords: Anti-infective agents. Intensive Care Unit. Bacteria.

\section{Introdução}

As infecções relacionadas à assistência à saúde (IRAS) são denominadas como aquelas que o indivíduo adquire durante o período referente à realização dos cuidados à saúde e representam uma das maiores problemáticas no âmbito da saúde pública no mundo. Segundo a Organização Mundial da Saúde (OMS), estas infecções ocorrem tanto em países em desenvolvimento quanto nos países desenvolvidos, a exemplo dos Estados Unidos da América, onde estima-se que ocorra cerca de 2 milhões de infecções relacionadas à assistência à saúde anualmente, ocasionando entre 60 e 90 mil mortes e custos hospitalares de aproximadamente 17 a 29 bilhões de dólares. ${ }^{(1)}$

As IRAS representam um dos principais motivos para elevação dos índices de morbidade e mortalidade. Essas podem ser ocasionadas pela microbiota do próprio paciente, ou por microorganismos presentes no ambiente hospitalar, disseminando-se rapidamente a depender das condições. Milhões de pacientes são acometidos por IRAS em todo o mundo a cada ano, levando a uma mortalidade expressiva e prejuízos financeiros para os sistemas de saúde. ${ }^{(2)}$
Países em desenvolvimento apresentam valores percentuais de IRAS maiores do que os valores advindos de países desenvolvidos; estimase que a cada 100 pacientes hospitalizados, sete pacientes em países desenvolvidos e 10 em países em desenvolvimento irão adquirir pelo menos uma IRAS. ${ }^{(3)}$ De acordo com a OMS, as taxas de prevalência nestas instituições variaram de $5 \%$ a $19 \%$, sendo a maior parte com dados superiores a $10 \%$. No Brasil, a prevalência alcança $14 \%{ }^{(4)}$

Atrelado a este fato, cerca de $70 \%$ destas infecções são causadas por bactérias resistentes ou multirresistentes. ${ }^{(5)}$ Importante ressaltar que o índice de IRAS varia expressivamente, pois está diretamente associado com o nível de atendimento e complexidade de cada unidade hospitalar, relacionando-se, assim, com a triagem de pacientes na admissão no hospital. ${ }^{(6)}$ Porém, devido à escassez de estudos e dados informativos a respeito destas infecções em diversos países pobres ou em desenvolvimento e emergentes, considera-se que estes índices possam estar subestimados.

Embora as causas de IRAS estejam intimamente relacionadas com a suscetibilidade do paciente frente à atmosfera hospitalar, bem como os métodos diagnósticos e terapêuticos 
utilizados, a principal causa ainda corresponde às condições de controle microbiano, higiene do ambiente hospitalar e a qualidade de colonização dos indivíduos hospitalizados.

Os hospitais são importantes reservatórios para uma variedade de patógenos e diferentes microrganismos, como bactérias, fungos e vírus. ${ }^{(7)}$ A identificação e o controle da microbiota hospitalar contribuem para reduções da morbidade e mortalidade de pacientes e dos custos hospitalares. Portanto é de fundamental importância a conscientização dos profissionais da saúde sobre o papel que desempenham na transmissão dessas infecções. ${ }^{(8)}$

Nas unidades de terapia intensiva (UTIs), as IRAS são uma preocupação constante pelo fato de ali serem mais frequentes e serem a maior causa de complicações nestes pacientes hospitalizados. ${ }^{(9)}$ A UTI é reconhecida como uma unidade de emergência e disseminação de micro-organismos resistentes, isso justifica-se por diversos fatores: é unidade restrita, há uma maior frequência de contato entre os profissionais e o paciente; há maior ocorrência de procedimentos invasivos (uso de dispositivos como sondas, cateteres, ventiladores mecânicos); existe um risco potencializado de transmissão cruzada entre patógenos; há uma alta pressão seletiva pelo uso de antibióticos de largo espectro; existência do emprego demasiado de terapia antimicrobiana de forma empírica; além da suscetibilidade dos pacientes, correspondente à sua situação clínica. ${ }^{(10)}$

Segundo dados da OMS, aproximadamente $30 \%$ dos pacientes em UTIs são afetados por pelo menos um episódio de IRAS. Quanto maior o período de permanência dos pacientes em UTI, maior o risco de esses indivíduos adquirirem uma infecção. ${ }^{(4)}$ Nestes locais, as drogas antimicrobianas assumem uma importância preponderante, na medida em que são os únicos fármacos que não afetam somente os pacientes que os utilizam, mas, também, interferem de forma significativa no ambiente hospitalar por alteração da ecologia microbiana. ${ }^{(11)}$

Poucos são os estudos referentes ao levantamento das infecções e seus respectivos patógenos adquiridos pelos indivíduos internados na UTI da instituição e mesmo em outros hospitais da região do Sertão de Pernambuco. ${ }^{(12)}$ Sendo assim, estas informações serão fundamentais para previsão, monitoramento, intervenções e revalidação de protocolos das comissões de controle de IRAS a fim de promover uma prescrição segura dos antimicrobianos em pacientes hospitalizados do hospital universitário (HU).

Diante do exposto, o objetivo deste trabalho foi avaliar a prevalência e perfil de sensibilidade antimicrobiana de bactérias isoladas de pacientes internados em Unidade de Terapia Intensiva de um hospital universitário do Sertão de Pernambuco.

\section{Metodologia}

A pesquisa trata-se de um estudo observacional, retrospectivo, descritivo, com abordagem quantitativa e de natureza clínica, baseado na avaliação dos resultados dos exames e diagnóstico microbiológico de culturas clínicas positivas para micro-organismos, realizadas na Unidade de Terapia Intensiva (UTI) do hospital universitário do Sertão de Pernambuco.

O hospital universitário, local da pesquisa, apresenta perfil assistencial de hospital geral de média e alta complexidade à comunidade adulta, com dimensionamento dos serviços assistenciais e de ensino e pesquisa. É considerado referência em traumas, politraumas, ortopedia, neurocirurgia, e clínicas geral e médica. A instituição conta com um número de 129 leitos, sendo 111 leitos destinados ao internamento de pacientes clínicos e cirúrgicos e 18 leitos de terapia intensiva. Do total de leitos, 37 são da especialidade traumato-ortopedia.

As amostras foram coletadas de pacientes admitidos no setor UTI. As coletas foram realizadas no período de janeiro a junho de 2019. A análise microbiológica, identificação fenotípica e perfil de suscetibilidade foram realizados no Laboratório de Análises Clínicas e Anatomia Patológica do hospital universitário. As amostras foram obtidas através da coleta dos respectivos materiais: sangue, aspirado traqueal e urina de pacientes internados 
na UTI Adulto. A identificação das espécies bacterianas e a antibiotipagem das cepas foram realizadas pelo sistema automatizado BD Phoenix ${ }^{\circledR}$ 100 (Becton Dickinson, New Jersey, EUA).

Foram consideradas amostras positivas para urocultura quando a contagem de colônias foi maior ou igual a $100.000 \mathrm{UFC} / \mathrm{ml}$, para hemocultura quando houve qualquer crescimento bacteriano e para cultura de secreção traqueal quando a contagem de colônias foi maior ou igual a $10^{6} \mathrm{UFC} / \mathrm{ml}$.

Os dados dos exames foram obtidos por meio de impressos laboratoriais do próprio serviço e tabulados. Nas amostras positivas foram analisadas as variáveis prevalência de bactérias e o perfil de sensibilidade e resistência aos antibióticos testados.

A pesquisa foi aprovada pelo Comitê de Ética em Pesquisa envolvendo seres humanos do Sistema CEP/Conep, por meio da Plataforma
Brasil e pelo Comitê de Ética e Deontologia em Estudos e Pesquisas (CEDEP-UNIVASF) sob o registro CAAE: 66493917.0.0000.5196.

\section{Resultados}

Durante o período de janeiro a junho de 2019, foram coletadas 394 amostras clínicas da UTI do HU-Univasf, provenientes de hemocultura (143), urocultura (116) e aspirado traqueal (135). Como demonstrado na Tabela 1, deste total, 36,5\% $(n=144)$ apresentaram crescimento bacteriano, sendo caracterizados como culturas positivas para pelo menos uma espécie bacteriana: 32 isolados de hemocultura, 91 de aspirado traqueal (AT) e 21 de urocultura. A amostra clínica com maior prevalência de culturas positivas foi o material de aspirado traqueal.

Tabela 1 - Distribuição das amostras clínicas da UTI com cultura positiva.

\begin{tabular}{lccc}
\hline Amostras & Total & Positivas & \% \\
\hline Hemocultura & 143 & 32 & 22,3 \\
Urocultura & 116 & 21 & 18,1 \\
Aspirado traqueal & 135 & 91 & 67,4 \\
\hline Total & 394 & 144 & 36,5 \\
\hline
\end{tabular}

Fonte: Autoras

Das 144 culturas positivas, 16 espécies bacterianas foram detectadas. Na Tabela 2 é possível observar a distribuição das espécies isoladas. A bactéria Acinetobacter baumannii apresentou maior prevalência entre as espécies isoladas das infecções ocorridas na UTI $(22,9 \%)$, seguida pelas espécies Pseudomonas aeruginosa (19,2\%) e Staphylococcus aureus (16,7\%).

Tabela 2 - Distribuição das espécies bacterianas identificadas nas amostras clínicas da UTI.

\begin{tabular}{lcccccccc}
\hline \multirow{2}{*}{ Micro-organismos } & \multicolumn{3}{c}{ Hemocultura } & \multicolumn{2}{c}{ Urocultura } & \multicolumn{2}{c}{ AT* } & \multicolumn{2}{c}{ Total } \\
& $\mathbf{n}^{\mathbf{0}}$ & $\mathbf{\%}$ & $\mathbf{n}^{\mathbf{0}}$ & $\mathbf{\%}$ & $\mathbf{n}^{\mathbf{0}}$ & $\mathbf{\%}$ & $\mathbf{n}^{\mathbf{0}}$ & $\mathbf{\%}$ \\
\hline $\begin{array}{l}\text { Staphylococcus } \\
\text { coagulase negativa (SCN) }\end{array}$ & 12 & 37,5 & - & - & - & - & 12 & 8,33 \\
$\begin{array}{l}\text { Staphylococcus aureus } \\
\text { Acinetobacter baumannii }\end{array}$ & 04 & 12,5 & 02 & 9,5 & 18 & 19,7 & 24 & 16,7 \\
& 05 & 15,6 & 03 & 14,2 & 25 & 27,4 & 33 & 22,9
\end{tabular}


Continuação

\begin{tabular}{lcccccccc} 
Klebsiella pneumoniae & 07 & 21,8 & 05 & 23,8 & 10 & 11,0 & 22 & 15,27 \\
Enterobacter cloacae & 02 & 6,2 & 02 & 9,5 & 04 & 4,4 & 08 & 5,55 \\
Enterococcus sp. & 01 & 3,1 & 02 & 9,5 & - & - & 03 & 2,08 \\
Escherichia coli & - & - & 05 & 23,8 & 04 & 4,4 & 09 & 6,25 \\
Pseudomonas aeruginosa & 01 & 3,1 & 02 & 9,5 & 16 & 17,6 & 19 & 13,2 \\
Proteus mirabilis & - & - & - & - & 02 & 2,2 & 02 & 1,38 \\
Stenotrophomonas maltophilia & - & - & - & - & 02 & 2,2 & 02 & 1,38 \\
Streptococcus mitis & - & - & - & - & 02 & 2,2 & 02 & 1,38 \\
Streptococcus agalactiae & - & - & - & - & 02 & 2,2 & 02 & 1,38 \\
Streptococcus anginosus & - & - & - & - & 02 & 2,2 & 02 & 1,38 \\
Proteus vulgaris & - & - & - & - & 01 & 1,0 & 01 & 0,7 \\
Streptococcus pneumoniae & - & - & - & - & 01 & 1,0 & 01 & 0,7 \\
Klebsiella ozaenae & - & - & - & - & 01 & 1,0 & 01 & 0,7 \\
Klebsiella aerogenes & - & - & - & - & 01 & 1,0 & 01 & 0,7 \\
\hline Total & 32 & 22,2 & 21 & 14,58 & 91 & 63,19 & 144 & 100 \\
\hline
\end{tabular}

Legenda: $\mathrm{AT}^{*}$ : aspirado traqueal.

Fonte: Autoras

No período de janeiro a junho de 2019 foram bacilos Gram-negativos (BGN). As espécies mais admitidas 143 amostras de hemocultura, destas, prevalentes entre as isoladas de hemocultura foram 32 foram positivas $(22,3 \%)$ e 111 foram negativas $(77,6 \%)$. os Staphylococcus coagulase negativa, com 37,5\% dos casos, seguidos de K. pneumoniae (21,9\%), A.

Dos micro-organismos isolados das hemobaumannii (15,6\%), S. aureus (12,5\%), Enterobacculturas positivas, $50 \%$ pertenceram ao grupo dos ter cloacae (6,3\%), Enterococcus faecalis $(3,1 \%) \mathrm{e}$ cocos Gram-positivos (CGP) enquanto 47\% foram Pseudomonas aeruginosa (3,1\%) (Gráfico 1).

Gráfico 1 - Frequência das espécies bacterianas isoladas em hemoculturas da UTI (\%).

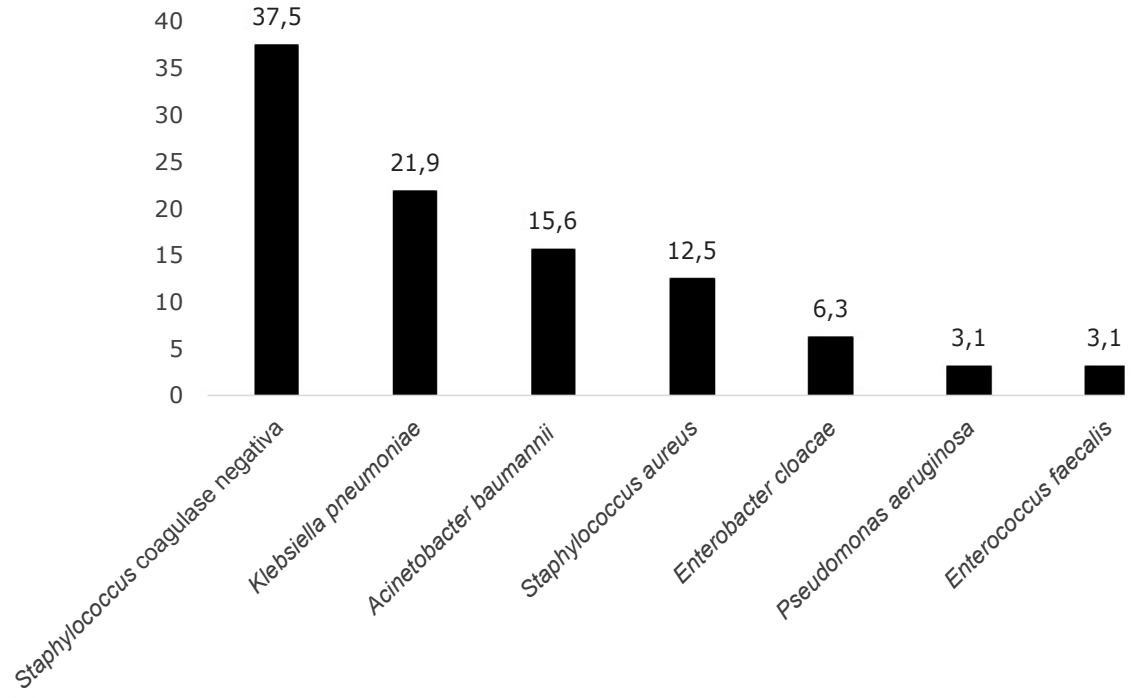

Fonte: Autoras 
Das 116 amostras de urina, em apenas 21 uroculturas positivas $(18,1 \%)$ houve identificação das espécies. No Gráfico 2 é possível notar que Escherichia coli e Klebsiella pneumoniae foram mais prevalentes em relação às demais bactérias isoladas, com uma frequência de isolamento de 23,8\%, seguidas por Acinetobacter baumannii com $14,3 \%$.

Gráfico 2 - Frequência das espécies bacterianas isoladas de uroculturas da UTI (\%).

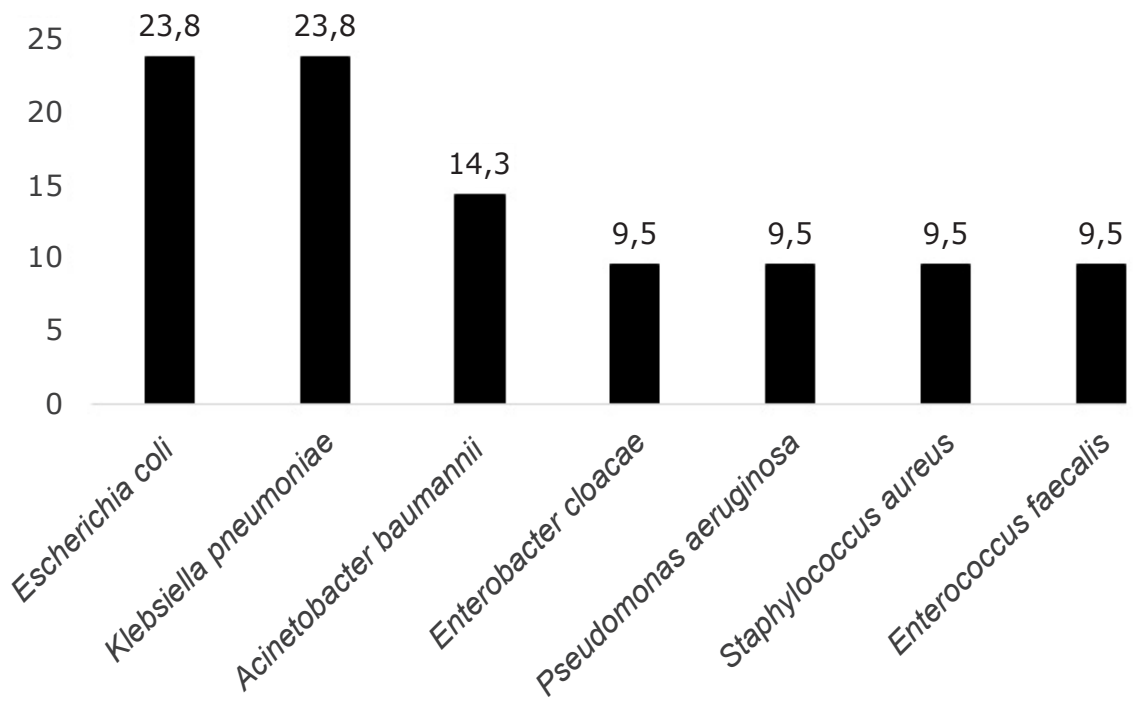

Fonte: Autoras

Das 135 amostras de aspirado traqueal, 91 foram positivas $(67,4 \%)$ e 44 foram negativas (32,5\%), sendo identificadas 13 espécies. Como demonstrado no Gráfico 3, A. baumannii ( $\mathrm{n}=25)$, $S$. aureus $(\mathrm{n}=18)$ e $P$. aeruginosa $(\mathrm{n}=16)$ foram as espécies mais prevalentes isoladas de aspirado traqueal dos indivíduos da UTI, com 27,4\%, 19,7\% e $17,6 \%$, respectivamente, das culturas positivas. Ademais, observou-se que diversas enterobactérias, tais como $K$. pneumoniae $(11,0 \%)$, E. coli e Enterobacter sp. apresentaram-se frequentes como isolados de AT. Entre os CGP, além do S. aureus, o grupo com mais ocorrência entre os isolados foi dos estreptococos, com sete amostras.

Gráfico 3 - Frequência das espécies bacterianas isoladas de aspirados traqueais da UTI (\%), (n=91).

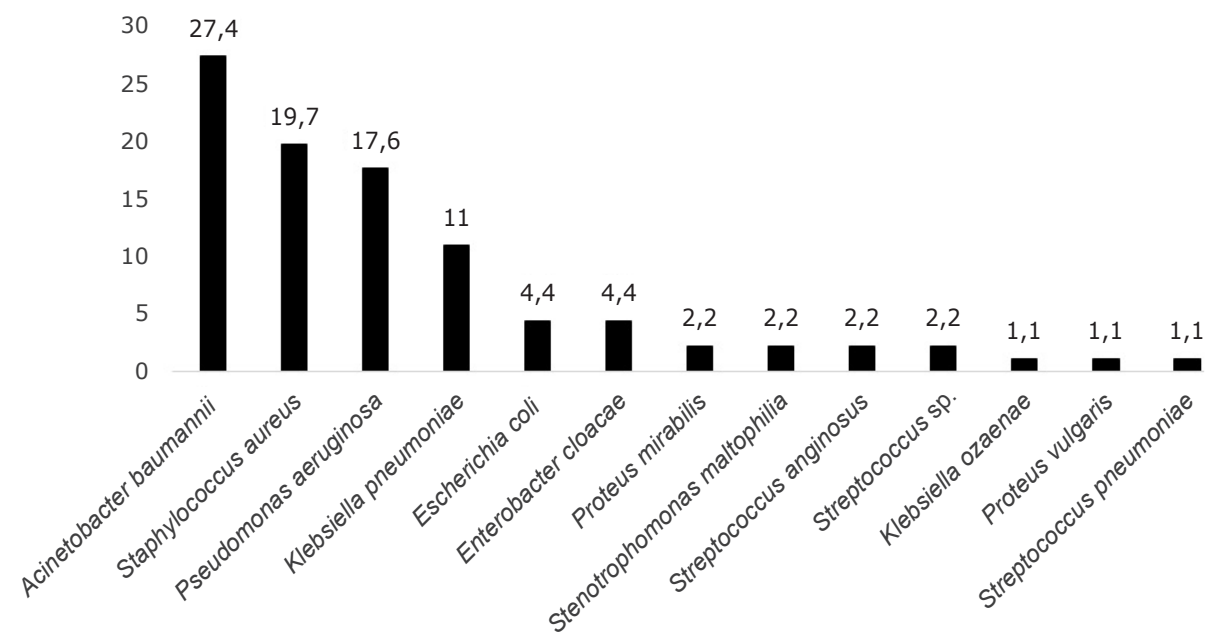

Fonte: Autoras 
No estudo, ao todo 144 antibiogramas foram avaliados após determinação e análise do perfil de sensibilidade e resistência dos isolados bacterianos detectados em culturas positivas da UTI, realizados pelo sistema automatizado BD Phoenix ${ }^{\circledR} 100$ (Becton Dickinson, New Jersey, EUA). De acordo com a metodologia do Clinical and Laboratory
Standards Institute (CLSI), ${ }^{(13)}$ os resultados foram classificados em sensível (S), resistente $(\mathrm{R})$ e intermediário (I).

As Tabelas 3 e 4 demonstram os perfis de sensibilidade das espécies clínicas isoladas da UTI coletados dos laudos realizados pelo sistema automatizado BD Phoenix ${ }^{\circledR} 100$.

Tabela 3 - Percentual de sensibilidade dos isolados clínicos da UTI coletados no laboratório de microbiologia do HU-Univasf para bactérias Gram-negativas.

\begin{tabular}{|c|c|c|c|c|c|c|c|}
\hline Antibióticos & $\begin{array}{c}\text { A. baumannii } \\
\begin{array}{c}(\mathrm{n}=33) \\
\%\end{array}\end{array}$ & $\begin{array}{c}\text { K. pneumoniae } \\
(\mathrm{n}=22) \\
\%\end{array}$ & $\begin{array}{l}\text { P. aeruginosa } \\
\qquad \begin{array}{c}(\mathrm{n}=19) \\
\%\end{array}\end{array}$ & $\begin{array}{l}\text { Enterobacter } \mathrm{sp} . \\
\qquad \begin{array}{c}(\mathrm{n}=08) \\
\%\end{array}\end{array}$ & $\begin{array}{c}\text { E. coli } \\
(\mathrm{n}=09) \\
\%\end{array}$ & $\begin{array}{l}\text { Proteus sp. } \\
\qquad \begin{array}{c}(\mathrm{n}=03) \\
\%\end{array}\end{array}$ & $\begin{array}{l}\text { S. maltophilia } \\
\qquad \begin{array}{c}(\mathrm{n}=02) \\
\%\end{array}\end{array}$ \\
\hline Amicacina & 12,1 & 100 & 88,2 & 100 & 100 & 100 & NT \\
\hline$A m p+s u b$ & 10 & 68,4 & NT & 0 & 25 & 66,7 & NT \\
\hline Cefepime & 12,1 & 77,2 & 77,7 & 75 & 55,6 & 66,7 & NT \\
\hline Ceftazidina & 12,1 & NT & 73,7 & NT & NT & NT & 50 \\
\hline Ciprofloxacino & 10 & 72,7 & 78,9 & 87,5 & 77,8 & 66,7 & NT \\
\hline Colistina & 100 & 100 & 84,6 & 100 & 100 & $0(n=2)$ & NT \\
\hline Doxiciclina & 100 & NT & 95 & NT & NT & NT & NT \\
\hline Gentamicina & 6,0 & 77,2 & 72,2 & 87,5 & 100 & 66,7 & NT \\
\hline Imipinem & 12,1 & 77,2 & 63,1 & 87,5 & 88,9 & $0(n=1)$ & NT \\
\hline Levofloxacino & 9,0 & 72,7 & 77,7 & 87,5 & 77,8 & 66,7 & 50 \\
\hline Meropenem & 18,1 & 77,2 & 72,2 & 100 & 88,9 & 100 & NT \\
\hline Pipe + tazo & 12,5 & 66,6 & 70,5 & 50 & 100 & 100 & NT \\
\hline $\mathrm{Smt}+\mathrm{tmp}$ & 27,2 & 66,6 & NT & 87,5 & 11,1 & 66,7 & 100 \\
\hline
\end{tabular}

Legenda: NT: não testado; n: número de isolados bacterianos; \%: percentual de resistência; amp + sub: ampicilina + sulbactam; pipe + tazo: piperacilina + tazobactam; smt + tmp: sulfametoxazol + trimetoprima.

Fonte: Autoras

Entre os isolados Gram-negativos de maior prevalência neste estudo, $A$. baumannii apresentou percentual reduzido de sensibilidade a quase todos os fármacos, com exceção da colistina e doxiciclina quando comparado ao perfil das outras espécies isoladas (Tabela 3). Os valores de resistência elevada aos carbapenemicos em mais de $80 \%$ dos isolados faz notar-se e serve de alerta ao uso mais frequente destes antibióticos na clínica e o aumento de cepas resistentes aos mesmos pela produção de carbapenemases.

Em contrapartida, outras espécies prevalentes como $P$. aeruginosa e K. pneumoniae apresentaram sensibilidade elevada à maioria dos antibióticos, incluindo a amicacina, doxiciclina, carbapenemicos e quinolonas. É preocupante, entretanto, o fato de ser detectada alguma resistência $(15,4 \%)$ à colistina nos isolados de $P$. aeruginosa. 
Tabela 4 - Percentual de sensibilidade dos isolados clínicos da UTI coletados no laboratório de microbiologia do HU-Univasf para bactérias Gram-positivas.

\begin{tabular}{lcccc}
\hline Antibióticos & $\begin{array}{c}\text { S. aureus } \\
(\mathrm{n}=24)\end{array}$ & $\begin{array}{c}\mathrm{SCN} \\
(\mathrm{n}=12) \\
\%\end{array}$ & $\begin{array}{c}\text { E. faecalis } \\
(\mathrm{n}=3)\end{array}$ & $\begin{array}{c}\text { Streptococcus sp.* } \\
(\mathrm{n}=5) \\
\%\end{array}$ \\
\hline Ampicilina & $0(\mathrm{n}=11)$ & $0(\mathrm{n}=6)$ & 100 & $0(\mathrm{n}=1)$ \\
Amp + sub & $100(\mathrm{n}=23)$ & $\mathrm{NT}$ & $\mathrm{NT}$ & $\mathrm{NT}$ \\
Cefepime & $\mathrm{NT}$ & $\mathrm{NT}$ & $\mathrm{NT}$ & $66,7(\mathrm{n}=3)$ \\
Ceftarolina & 87,5 & $\mathrm{NT}$ & 0 & $\mathrm{NT}$ \\
Ceftriaxona & $100(\mathrm{n}=1)$ & $\mathrm{NT}$ & $\mathrm{NT}$ & 80 \\
Ciprofloxacino & $\mathrm{NT}$ & $\mathrm{NT}$ & $50(\mathrm{n}=2)$ & $\mathrm{NT}$ \\
Clindamicina & $60,9(\mathrm{n}=23)$ & 25 & $\mathrm{NT}$ & 60 \\
Daptomicina & $100(\mathrm{n}=6)$ & $100(\mathrm{n}=11)$ & 100 & $\mathrm{NT}$ \\
Levofloxacino & $\mathrm{NT}$ & $\mathrm{NT}$ & $\mathrm{NT}$ & $100(\mathrm{n}=4)$ \\
Linezolide & 100 & 91,7 & 100 & $\mathrm{NT}$ \\
Oxacilina & 83,3 & $\mathrm{NT}$ & $\mathrm{NT}$ & $\mathrm{NT}$ \\
Penicilina & $0(\mathrm{n}=21)$ & $0(\mathrm{n}=8)$ & $\mathrm{NT}$ & $100(\mathrm{n}=1)$ \\
Rifampicina & 91,7 & 75 & $\mathrm{NT}$ & $\mathrm{NT}$ \\
Smt + tmp & 79,2 & 33,3 & $\mathrm{NT}$ & $\mathrm{NT}$ \\
Tetracilina & $100(\mathrm{n}=1)$ & $\mathrm{NT}$ & $\mathrm{NT}$ & $25(\mathrm{n}=4)$ \\
Tigeciclina & $100(\mathrm{n}=21$ & $\mathrm{NT}$ & 100 & $\mathrm{NT}$ \\
Vancomicina & 100 & 100 & 100 & $100(\mathrm{n}=3)$ \\
\hline
\end{tabular}

Legenda: NT: não testado; n: número de isolados bacterianos; \%: percentual de resistência; SCN: Staphylococcus coagulase negativa; Streptococcus sp. ${ }^{*}=$ S. pneumoniae, S. anginosus, S. mitis; amp + sub: ampicilina + sulbactam; smt + tmp: sulfametoxazol + trimetoprima.

Fonte: Autoras

Entre os isolados Gram-positivos com mais frequência nas amostras, estão os Staphylococcus aureus e cepas de Staphylococcus coagulase negativa. Na Tabela 4 pode-se notar ausência de sensibilidade às penicilinas e à ampicilina. Os dados revelam também algum grau de resistência à oxacilina (17\%), sugerindo que cepas MRSA (Staphylococcus aureus resistente à meticilina) possam estar circulando neste ambiente hospitalar. Pode-se observar que todas foram sensíveis à daptomicina, tigeciclina e vancomicina.

Os dados da Tabela 5 demonstram a distribuição das bactérias totais isoladas de cada amostra clínica a fim de permitir a análise de uma tendência do perfil de resistência destes microrganismos.

Tabela 5 - Distribuição da resistência aos antimicrobianos dos isolados nas amostras clínicas.

\begin{tabular}{lccc}
\hline Antibióticos & $\begin{array}{c}\text { Aspirado traqueal } \\
(\mathbf{n}=\mathbf{9 1})\end{array}$ & $\begin{array}{c}\text { Hemocultura } \\
(\mathbf{n}=\mathbf{3 2})\end{array}$ & $\begin{array}{c}\text { Urocultura } \\
(\mathbf{n}=\mathbf{2 1})\end{array}$ \\
\hline Amicacina & $37,1(\mathrm{n}=62)$ & $33,3(\mathrm{n}=15)$ & $17,6(\mathrm{n}=17)$ \\
Ampicilina & $94,3(\mathrm{n}=35)$ & $94,1(\mathrm{n}=17)$ & $80(\mathrm{n}=15)$ \\
Amp + sub & $63,6(\mathrm{n}=44)$ & $75(\mathrm{n}=12)$ & $75(\mathrm{n}=8)$
\end{tabular}


Continuação

$\begin{array}{lccc}\text { Cefepime } & 42,6(\mathrm{n}=68) & 60(\mathrm{n}=15) & 46,7(\mathrm{n}=15) \\ \text { Ceftazidina } & 60,5(\mathrm{n}=43) & 83,3(\mathrm{n}=6) & 60(\mathrm{n}=5) \\ \text { Ciprofloxacino } & 44,6(\mathrm{n}=65) & 60(\mathrm{n}=15) & 36,8(\mathrm{n}=19) \\ \text { Colistina } & 8,5(\mathrm{n}=47) & 0(\mathrm{n}=13) & 0(\mathrm{n}=8) \\ \text { Gentamicina } & 45,3(\mathrm{n}=64) & 53,3(\mathrm{n}=15) & 23,5(\mathrm{n}=17) \\ \text { Imipinem } & 43,5(\mathrm{n}=62) & 60(\mathrm{n}=15) & 23,5(\mathrm{n}=17) \\ \text { Levofloxacino } & 70,4(\mathrm{n}=71) & 53,3(\mathrm{n}=15) & 41,2(\mathrm{n}=17) \\ \text { Meropenem } & 37,5(\mathrm{n}=64) & 60(\mathrm{n}=15) & 29,4(\mathrm{n}=17) \\ \text { Pipe + tazo } & 42,1(\mathrm{n}=57) & 53,8(\mathrm{n}=13) & 17,6(\mathrm{n}=17) \\ \text { Smt }+ \text { tmp } & 41,8(\mathrm{n}=67) & 50(\mathrm{n}=30) & 64,7(\mathrm{n}=17)\end{array}$

Legenda: Amp + sub: ampicilina + sulbactam; pipe + tazo: piperacilina + tazobactam; smt + tmp: sulfametoxazol + trimetoprima.

Fonte: Autoras

É possível notar uma elevada resistência à ampicilina nos isolados de todas as amostras clínicas, variando de $80 \%$ a $94 \%$; cabe salientar que algumas bactérias apresentam resistência intrínseca a alguns antibióticos, como é o caso da K. pneumoniae à ampicilina - este antibiótico não desempenha função em bactérias produtoras de beta-lactamase. ${ }^{(14)}$

Nota-se, do mesmo modo, valores de resistência relevantes ao antimicrobiano ciprofloxacino, aos carbapenêmicos imipenem e meropenem, e à piperacilina + tazobactam. Os isolados de hemoculturas apresentaram valores acima de 50\% para estes antimicrobianos, variando entre $54 \%$ e $60 \%$; os aspirados traqueais também apresentaram valores elevados, variando entre $38 \%$ e $45 \%$, e as uroculturas variam entre $18 \%$ e $37 \%$.

Além disso, os dados demonstram que os isolados da UTI do hospital universitário ainda apresentam um perfil de sensibilidade elevada à colistina (polimixina E), sugerindo seu uso como fármaco alternativo nas terapias.

\section{Discussão}

Em relação à distribuição das amostras clínicas, uma pesquisa realizada em uma UTI de Recife, Pernambuco, evidenciou que a cultura de secreção traqueal foi a amostra com maior índice de positividade $(92,9 \%)$, de um total de 127 amostras, dados que corroboram os resultados do presente trabalho. ${ }^{(15)}$ A pneumonia associada ao ventilador mecânico (PAV) é uma infecção do parênquima pulmonar causada por diferentes agentes etiológicos. Esta infecção é resultado de um desequilíbrio entre mecanismos do sistema e patógenos e pode constituir uma causa significativa de morbidade e mortalidade, principalmente em idosos e/ou indivíduos imunocomprometidos. ${ }^{(15)}$ Estudos abrangendo secreções traqueais foram realizados recentemente no HU de Petrolina, em Pernambuco, e destacaram que dentre os principais micro-organismos isolados nessas culturas estão os bacilos Gram-negativos (Pseudomonas sp. e Acinetobacter sp.) e os cocos Gram-positivos (Staphylococcus aureus), sendo os Gram-negativos responsáveis por mais de $60 \%$ dos casos relatados e S. aureus entre $20 \%$ e $40 \%$ dos casos. ${ }^{(12)}$ Estes dados são semelhantes aos encontrados neste estudo. De acordo com os resultados reportados na Tabela 2, 72,5\% das espécies isoladas dos aspirados traqueais eram $\mathrm{BGN}$, incluindo enterobactérias e BGN não fermentadores, e 19,7\% das amostras eram positivas para $S$. aureus.

Em relação à distribuição das espécies, a bactéria $A$. baumannii foi a mais frequente. Essa espécie apresenta grande importância no manejo da prática clínica. Esses micro-organismos são 
hábeis em perdurar no ambiente hospitalar em lugares distintos e por períodos de tempo mais longos; isso se deve ao fato das suas poucas exigências nutricionais e à manifestação de fatores de virulência, que permite sua sobrevivência e adaptação ao ambiente hospitalar, incluindo a habilidade em captar o ferro do meio ambiente e sobreviver assim em condições de déficit de ferro, resistência à secagem, produção de uma cápsula polissacarídica em algumas estirpes e a capacidade de aderência a diferentes superfícies pela formação de biofilmes. ${ }^{(16)}$

Já em relação à distribuição das bactérias Gram-positivas, os Staphylococcus aureus foram os mais frequentes. Essa espécie coloniza e infecta o paciente, principalmente os que ficam internados por longo período. A invasão desses micro-organismos na traqueia estéril geralmente leva ao desenvolvimento de IRAS. Dentre estas, a pneumonia é a segunda causa mais corriqueira e a primeira em pacientes internados em UTIs, representando $50 \%$ das infecções, sendo a maioria por pneumonia associada ao ventilador mecânico, em função da maior prevalência de fatores de risco, tais como: população de imunocomprometidos, procedimentos invasivos e uso indiscriminado de antibióticos.

A espécie $P$. aeruginosa foi a terceira mais prevalente nos aspirados traqueais, ficando atrás de $A$. baumannii e $S$. aureus (17,6\%) (Gráfico 3). As taxas de colonização por $P$. aeruginosa nas regiões da mucosa e pele de pacientes hospitalizados que estejam em uso de antibióticos de amplo espectro, tratamento quimioterápico ou que utilizam mecanismo artificial de respiração pode ultrapassar $50 \%$; as infecções causadas por $P$. aeruginosa são usualmente de origem hospitalar e esta espécie é classificada como um patógeno oportunista. ${ }^{(17)}$ A bactéria contamina, na maioria das vezes, pacientes com o sistema imunológico comprometido, destacando-se prevalência acentuada em pacientes com idade avançada e em pacientes que apresentam alguma comorbidade. A maior parte dos equipamentos e materiais hospitalares, particularmente com umidade, assim como locais úmidos do corpo, naturalmente servem como um reservatório para este micro-organismo. Isso pode provocar a disseminação em todo o ambiente hospitalar e comunidade através de altas de pacientes ou póstransferências de leitos. A relação entre colonização por micro-organismo resistente e os fatores de risco dos pacientes evidencia a necessidade de monitorização e criação de protocolos que visem o apoio às medidas de controle da disseminação desses micro-organismos. ${ }^{(18)}$

Da família Enterobacteriaceae, a espécie de $K$. pneumoniae também apresentou razoável prevalência entre os indivíduos colonizados (11\%) (Gráfico 3). Seu mecanismo de colonização nos indivíduos possivelmente ocorre por contato com as diferentes fontes ambientais e pode ser encontrada colonizando a orofaringe e fezes de pessoas saudáveis. No organismo de pessoas imunocomprometidas esta bactéria encontra um ambiente favorável para seu desenvolvimento, levando aos quadros de infecção. ${ }^{(19)}$

Em relação às hemoculturas, observou-se perfis diversificados em estudos realizados em alguns hospitais brasileiros e tais dados sugerem que não há um perfil geral destes exames. Em um hospital localizado na Região Leste do estado de Minas Gerais verificou-se o índice de 18,60\% hemoculturas positivas, enquanto noutro estudo realizado em uma UTI de um hospital-escola de Goiânia, Goiás, constatou-se que 7,69\% das hemoculturas realizadas apresentaram crescimento microbiano. Em uma rede de hospitais privados de Fortaleza, no Ceará, o índice de hemoculturas positivas equivale a $55,94 \%$, já em outro estudo realizado em um hospital filantrópico de Alfenas, Minas Gerais, 47,52 \% foram positivas..$^{(20-23)}$

Verificou-se uma grande diversidade de bactérias identificadas em hemoculturas no presente trabalho, corroborando diferentes pesquisas. Além das mais frequentes, pode-se observar a ocorrência de espécies pouco citadas em outros estudos, mas com grande potencial de risco aos pacientes, como Staphylococcus hominis, Staphylococcus saprophyticus e Staphylococcus epidermidis. ${ }^{24-26)}$ 
Os Staphylococcus coagulase negativa, que constituem o grupo representante da microbiota humana e que atualmente também estão relacionados a casos sérios de infecções, vêm sendo motivo de muitos estudos. A importância desses microorganismos encontra-se principalmente pelo fato de serem os patógenos mais comuns responsáveis por bacteremia em recém-nascidos de baixo peso, por causarem excesso de mortalidade e por aumentarem o tempo de hospitalização. ${ }^{(27)} \mathrm{O}$ isolamento de Staphylococcus coagulase negativa em amostras de hemocultura com sinais e sintomas de sepse é, sem dúvida, significativo, porém, com muita frequência pode denotar à ocorrência de contaminação no período da coleta. Para se fazer o diagnóstico, é aconselhável o isolamento do Staphylococcus coagulase negativa em pelo menos duas amostras de sangue, com resistência a mais de seis antibióticos, incluindo a meticilina; ou ainda, identificando o mesmo Staphylococcus coagulase negativa em duas amostras, coletadas simultaneamente de dois locais diferentes. Ressaltase que o Staphylococcus coagulase negativa, que é detectado após quarenta e oito horas de incubação, é frequentemente um caso de contaminação. ${ }^{(27)}$

Ao mesmo tempo em que, em certos casos o Staphylococcus coagulase negativa presente na pele pode ser coletado junto com o sangue, não estando associado a nenhum processo infeccioso, em outros casos essas bactérias podem ser coletadas a partir do sangue, estando diretamente associadas a processos infecciosos sérios. Dessa forma, criase a grande dúvida para os médicos na hora da interpretação dos resultados. ${ }^{(27)}$

Em relação às uroculturas, Escherichia coli é o agente mais frequente envolvido em infecções urinárias, sendo responsável por $90 \%$ ou mais das infecções adquiridas na comunidade. É uma bactéria colonizadora do cólon, região perianal; nas mulheres, introito vaginal e região periuretral. Possui propriedades uropatogênicas específicas responsáveis pela invasão do trato urinário, assim como cepas não patogênicas; também são responsáveis pelo processo de infecção urinária, particularmente nos pacientes com anormalidades do trato urinário ou quando os mecanismos de defesa estão abalados, como é o caso dos idosos, crianças, gestantes e imunodeprimidos. ${ }^{(28)}$

No que se refere à resistência das espécies bacterianas analisadas no presente trabalho, sabese que ela ocorre por diferentes mecanismos. A Escherichia coli apresenta vários mecanismos de resistência; em meio a estes tem-se a habilidade de mutação cromossomial que leva à modificação de estruturas alvo de macromoléculas do antibiótico como ribossomos, proteínas e constituintes da parede celular. ${ }^{(29)}$ As bactérias sintetizam alvos cada vez menores ou simplesmente não os codificam. Em ocorrência disso, o fármaco não se liga à célula e não a penetra, logo não desempenha seu papel celular e em consequência o reconhecimento do fármaco pelo alvo fica afetado e sua potência diminuída. Outro mecanismo relacionado à mutação é a alteração da estrutura da membrana celular, diminuindo sua permeabilidade ao antibiótico. Existe ainda a capacidade da produção de bombas de resistência a múltiplos fármacos, onde a bactéria é capaz de bombear o antibiótico para fora da célula. ${ }^{(29)}$

Infecções causadas por cepas de Klebsiella pneumoniae têm tratamento difícil pela existência de cepas com plasmídeos, que codificam enzimas beta-lactamases de espectro estendido (ESBLs), conferindo resistência às drogas beta-lactâmicas; incidências maiores têm sido observadas em surtos epidêmicos hospitalares. ${ }^{(30)}$

Quanto aos mecanismos de resistência desenvolvidos pelo gênero $K$. pneumoniae, observou-se que além da produção da enzima carbapenemase, a resistência pode acontecer devido à alteração de porinas ocasionando resistência aos antibióticos imipenem e meropenem, pois por apresentarem moléculas grandes possuem maior dificuldade em penetrar no microrganismo, além do uso das bombas de efluxo. Já para o ertapenem, o mecanismo de resistência é a produção de carbapenemases e na perda de proteínas da membrana externa; e com relação às cefalosporinas de terceira geração, sua resistência está relacionada à beta-lactamase de espectro estendido (ESBL). ${ }^{(31)}$ 
A bactéria $A$. baumannii apresenta mecanismo de resistência similar a outras bactérias Gramnegativas já citadas neste texto. Esta bactéria apresenta alguns mecanismos de ação como a produção de uma cefalosporina e tipo AmpC denominada $\mathrm{ADC}$, que quando é produzida em altas taxas produz resistência à cefalotina, piperacilina, cefotaxima, ceftazidima e aztreonam, porém sem afetar os carbapenêmicos. ${ }^{(32)}$ Outro mecanismo é a produção de beta-lactamases e a presença de bombas de efluxo, sendo este último responsável pela resistência a carbapenêmicos e aminoglicósidos, macrólideos, cloranfenicol, tigeciclina, tetraciclinas, fluoroquinolonas e trimetoprim. Por último, tem-se o mecanismo relacionado à proteína de ligação à penicilina (PB2a e PB2b), já citado anteriormente, que leva à resistência dessa bactéria ao imipenem e meropenem. ${ }^{(32)}$

Quanto às cepas de $S$. aureus, relaciona-se como principal mecanismo de resistência a adesão ao gene mecA, que codifica as proteínas ligadoras de penicilina (PBP) e aumenta a resistência dessas bactérias aos beta-lactâmicos. A inibição de $S$. aureus aos beta-lactâmicos resulta nas MRSA, desse modo a síntese da parede celular continua ativa mesmo que haja alta concentração destes antibióticos. $^{(33)}$

Quanto às $P$. aeruginosa, a resistência aos carbapenêmicos tem sido associada principalmente à falta de permeabilidade porina (OprD), ao aumento da expressão das bombas de efluxo (MexAB-OprD) e à produção de metaloenzimas. Além disso, aos outros antimicrobianos a bactéria $P$. aeruginosa desenvolve vários mecanismos de resistência, como beta-lactamases de amplo espectro, metalo-beta-lactamases (MBL), alteração de proteínas ligadoras da penicilina, mutações por porinas, modificação enzimática plasmídica, mutação no DNA-girase e bombas de efluxo. ${ }^{(34)}$

Os bacilos Gram-negativos são as espécies mais frequentes isoladas de UTI, destacando-se A. baumannii, $P$. aeruginosa e $K$. pneumoniae. No entanto, a prevalência de $S$. aureus e de Staphylococcus coagulase negativa é maior em cultura de secreção respiratória e hemocultura, respectivamente, quando comparadas com isolados de enterobactérias. Os isolados de BGN presentes no hospital universitário do Sertão de Pernambuco apresentam um perfil de sensibilidade reduzida aos fármacos beta-lactâmicos, particularmente ampicilina e carbapenêmicos. Entre os CGP é possível determinar um perfil de resistência elevado aos beta-lactâmicos ampicilina e penicilina, bem como a detecção de cepas resistentes à oxacilina, sugerindo a circulação de cepas MRSA na UTI.

Independente da origem da amostra clínica, o perfil de sensibilidade à colistina (polimixina E) é elevado, permitindo assim o emprego deste antibiótico como terapia alternativa sobre as cepas ESBLs e resistentes aos carbapenens.

Logo, devido ao aumento cada vez maior da resistência bacteriana, e ao desenvolvimento de diferentes mecanismos de resistência produzidos pelas bactérias - como pode ser observado neste trabalho, deve-se ter uma atenção especial ao ambiente da UTI, evitando realizar os principais fatores que levam à resistência, como o uso indiscriminado de antimicrobianos, dose e tempo inadequados, associações desnecessárias e escolha inadequada das drogas na ausência de culturas.

Por conseguinte, os dados obtidos permitem reconhecer a frequência das espécies de bactérias mais isoladas envolvidas em IRAS na UTI, bem como determinar um perfil de sensibilidade aos antibióticos utilizados no setor, contribuindo para monitorar, direcionar e implantar metodologias de antibioticoterapia racional aos pacientes ali internados.

\section{Referências}

1 World Health Organization. Guidelines on Hand Hygiene in Health Care. Geneva: World Health Organization; 2009.

2 Miller AC, Polgreen LA, Polgreen PM. Optimal Screening Strategies for Healthcare Associated Infections in a Multi-Institutional Setting. PLoS Comput Biol. 2014;10(1). doi: 10.1371/journal. pcbi. 1003407. 
3 Agência Nacional de Vigilância Sanitária. Programa Nacional de Prevenção e Controle de Infecções Relacionadas à Assistência à Saúde (2016-2020). Brasília: ANVISA; 2016.

4 World Health Organization. The Burden of Health Care-Associated Infection Worldwide: A Summary. Geneva (CHE): World Health Organization; 2010.

5 Ferreira NLV, Nolasco ML, Espíndula BM. Principais infecções hospitalares que se desenvolvem nas Unidades de Terapia Intensiva (UTI) e quais os procedimentos básicos para evitar sua proliferação. Revista Eletrônica de enfermagem [internet]. 2010; 1(1):1-13. Disponível em: http://www.ceen. com.br/revistaeletronica

6 Giunta APN, Lacerda RA. Inspeção dos Programas de Controle de Infecção Hospitalar dos serviços de saúde pela Vigilância Sanitária: diagnostico de situação. Rev Esc Enferm USP. 2006; 40(1):64-70. doi: 10.1590/S008062342006000100009 .

7 Leopoldo VC, Andrade D, Hass VJ. Ocorrência de bactérias multiresistentes em um centro de terapia intensiva de hospital brasileiro de emergências. Rev Bras Ter Intensiva. 2006; 18(1): 4-12. doi: 10.1590/S0103-507X2006000 100006 .

8 Paula JD Junior, Gonçalves JC, Tinoco ALA, Coelho RO, Peron GR. Identificação e perfil de sensibilidade de bactérias em garrotes de uso hospitalar. Rev Ciênc Farm Básica Apl. 2013; 34(2):269-73.

9 Rocha LF, Leme NA, Brasileiro ME. A Atuação da Comissão de Controle de Infecção em Serviços de Saúde na Unidade de Terapia Intensiva: $O$ que fazer? Rev. Eletr. Enf. Centro de Estudos de Enfermagem e Nutrição [internet]. 2010; 1(1):1-16. Disponível em: http://www.ceen.com.br/revistaeletrônica

10 Oliveira AC, Wanessa TC, Thabata CL, Glaucia HM. Infecções hospitalares e resistência microbiana e imunidade de cuidados intensivos de um hospital universitário. Braz J Nurs. 2006; 5(2). doi: https://doi.org/10.5935/16764285.2006311
11 Tavares, W. Antibióticos e Quimioterápicos Para o Clínico. São Paulo: Atheneu; 2006.

12 Naue CR, Ribeiro T, Ribeiro R, Batista K, Aquino S. Ocorrência e perfil bacteriano de culturas coletadas em pacientes internados na unidade de terapia intensiva em um hospital terciário. HU Rev. 2019; 45(2): 122-33. doi: 10.34019/1982-8047.2019.v45.25933.

13 Clinical and Laboratory Standards Institute. Performance standards for antimicrobial susceptibility testing. Document M100-S19. Wayne (PA); 2009.

14 Soares LA, Nishi CYM, Wagner HL. Isolamento das bactérias causadoras de infecções urinárias e seu perfil de resistência aos antimicrobianos. Rev. Bras Med Fam e Com. 2006; 2(6).

15 GomesAC,CarvalhoPO,LimaETA, GomesET, Valença MP, Cavalcanti ATA. Caracterização das infecções relacionadas à assistência à saúde em unidade de terapia intensiva. Rev. Enf UFPE on line [internet]. 2014; 8(6):157785. Disponível em: https://periodicos.ufpe. $\mathrm{br} / \mathrm{revistas} / \mathrm{revistaenfermagem/article/}$ viewFile/9848/10059

16 Canzi KR, Colacite J. Frequência de pneumonia associada à ventilação mecânica com base em resultados de culturas quantitativas de secreções traqueais. RBAC. 2016; 48(2):11822.

17 Pimentel NMS. Infeções em Cateteres de Hemodialisados [tese]. Porto (PRT): Universidade Fernando Pessoa; 2014.

18 Arcanjo R, Oliveira AC. Fatores associados à colonização axilar por microrganismo resistente em pacientes na Unidade de Terapia Intensiva. Rev. Atenção à Saúde. 2017; 15(51):11-7. doi: 10.13037/ras.vol15 n51.3941.

19 Paula VG, Quintanilha LV, Silva FAC, Rocha HF, Santos FL. Enterobactérias produtoras de carbapenemase: prevenção da disseminação de superbactérias em UTI's. Universitas: Ciênc. Saúde. 2016; 14(2):175-85. doi: 10.5102/ucs. v14i2.3847. 
20 Cunha MN, Linardi VR. Incidence of bacteremia in a tertiary hospital in eastern Minas Gerais. Rev Med Minas Gerais. 2013; 23(2):146-50. doi: 10.5935/2238- 3182.2013 0024 .

21 Sousa MA, Medeiros NM, Carneiro JR, Cardoso AM. Hemoculturas positivas de pacientes da unidade de terapia intensiva de um hospital escola de Goiânia - GO. Rev. Est Vida e Saúde. 2014; 41(3):627-35. doi: 10.18224/est.v41i3.3612.

22 Reis HPLC, Vieira JB, Magalhães DP, Sartori DP, Fonseca DB, Viana JM, et al. Avaliação da resistência microbiana em hospitais privados de Fortaleza - Ceará. Rev Bras Farm. 2013; 94(1):83-7.

23 Damasceno DD, Terra FS, Dutra PO, Libânio SIC. Perfil da incidência bacteriana e resistência antimicrobiana em uma instituição hospitalar. Rev Min Enferm. 2008; 12(1):1049. doi: S1415- 27622008000100015.

24 Alves NLS, Oliveira CR, Silva LAP, Gervásio SMD, Alves SR, Sgavoli GM. Hemoculturas: estudo da prevalência dos microrganismos e o perfil de sensibilidade dos antibióticos utilizados em Unidade de Terapia Intensiva. J Health Sci Institute. 2012; 30(1):44-7.

25 Freire ILS, Araujo RO, Vasconcelos QLD, Menezes LCC, Costa IKF, Torres GV. Perfil microbiológico de sensibilidade bacteriana das hemoculturas de unidade de terapia intensiva pediátrica. Rev Enferm UFSM. 2013; 3(3):42939. doi: 10.5902/217976928980.

26 Magalhães LS, Abreu ES, Pussente CG, Oliveira CGA. Incidência e perfil de sensibilidade e resistência das estirpes bacterianas isoladas das hemoculturas de um hospital oncológico. Rev. Cient Faminas. 2014; 10(2):39-53.

27 Silbert S, Rosa DD, Matte U, Goldim JR, Barcellos SH, Procianoy R. Staphylococcus sp coagulase negativa em hemoculturas de pacientes com menos de sessenta dias de idade: infecção versus contaminação? J Pediatria. 1997; 73(3):161-5.
28 Silveira SA, Araújo MC, Fonseca FM, Okura MH, Oliveira ACS. Prevalência e suscetibilidade bacteriana em infecções do trato urinário de pacientes atendidos no Hospital Universitário de Uberaba. RBAC. 2010; 42(3): 157-60.

29 Oliveira ALD, Soares MM, Santos TCD, Santos A. Mecanismos de resistência bacteriana a antibióticos na infecção urinária. Rev. Uningá. 2014; 20(3):65-71.

30 French GL, Shannon KP, Simmons N. Hospital outbreak of Klebsiella pneumoniae resistant to broad-spectrum cephalosporins and b-lactamb-lactamase inhibitor combinations by hiperproduction of SHV-5 b-lactamase. J. clin. Microbiol. 1996; 34: 358-63.

31 Oliveira ACC, Silva ACO. Prevalência de infecção do trato urinário relacionada ao cateter vesical de demora em pacientes de UTI. Rev. Pesq. em Saúde. 2010; 11(1):27-31.

32 Munera JMV, Villamil GR, Quiceno JNL. Acinetobacter baumannii: importancia clínica, mecanismos de resistencia y diagnóstico. CES Medicina. 2014; 28(2):233-46.

33 Baptista MGFM. Mecanismos de Resistência aos Antibióticos [tese]. Lisboa, Portugal: Universidade Lusófona de Humanidades e Tecnologias; 2013.

34 Ochoa SA, Lopez-Montiel F, Escalona G, Cruz-Córdova A, Dávila LB, LópezMartínez B, et al. Pathogenic characteristics of Pseudomonas aeruginosa strains resistant to carbapenems associated with biofilm formation. Bol Med del Hospital Infantil de Mexico. 2013; 70(2):138-50. 